\title{
O pensamento dos militares em política internacional (1961-1989)
}

\author{
EUGÊNIOVARGAS GARCIA*
}

Uma questão de fundo pode ser levantada entre estudiosos das relações internacionais do Brasil: existiria um pensamento genuinamente brasileiro em política internacional? Na hipótese de que esse pensamento de fato exista, poderia ser indagado, de um lado, se a teoria seria um dos elementos a colaborar na sua elaboração e, de outro, em que segmentos da sociedade brasileira deveriam ser buscadas suas raízes intelectuais.

Excluindo da esfera da teoria das relações internacionais as teorias da dependência, do imperialismo e suas derivações, Amado Luiz Cervo conclui pela existência, no Brasil, de um pensamento sem teoria. Esse pensamento fluiria de vertentes heterogêneas: a intelectualidade, o meio político e diplomático, o militar e outras lideranças sociais. Gelson Fonseca Jr., por seu turno, identifica no “modo brasileiro" de refletir sobre relações internacionais a busca de uma compreensão específica do andamento da Política Externa do país. A teoria, mais uma vez, ficaria em segundo plano ${ }^{1}$.

Guardadas as devidas diferenças no grau de envolvimento com a ação diplomática propriamente dita enas suas respectivas vinculações institucionais(no âmbito do Estado ou fora dele), três segmentos da sociedade brasileira assumem posição de relevo nas discussões afetas às relações internacionais: acadêmicos, diplomatas e militares ${ }^{2}$. Este artigo pretende abordar, de modo muito genérico, questões relacionadas à evolução do pensamento destes últimos em matéria de política internacional e política externa, restringindo o escopo da análise ao período 1961-1989, em função do interesse histórico que tal corte cronológico apresenta ao observador situado nos anos $1990^{3}$. Muito já se produziu, na área de estudos estratégicos, a respeito de temas relacionados à geopolítica eà segurança nacional no pensamento dosmilitares brasileiros. Há, no entanto, poucos trabalhos específicos

Rev. Bras. Polít. Int. 40 (1): 18-40 [1997].

* Mestre em História das Relações Internacionais pela Universidade de Brasília e diplomata. 
sobre a visão militar das relações internacionais e seus reflexos na Política Exterior do Brasil.

Após algumas considerações metodológicas de definição do objeto de estudo e de sua importância (item 1), serão expostas algumas das limitações da interpretação crítica tradicional, a qual ainda parece informar determinadas tentativas de compreensão da presença militar na vida nacional (item 2). A partir da concepção de política internacional prevalecente na doutrina das Forças Armadas (item 3), e tomando por base ilações extraídas da história recente da Política Externa brasileira, buscar-se-á ressaltar traços distintivos que marcaram o pensamento dos militares, incluindo sua vinculação com o projeto nacionaldesenvolvimentista(item4).

\section{Militares e relações internacionais}

Para os objetivos deste artigo, uma distinção conceitual será feita entre quatro termos correlatos, muitas vezes utilizados como sinônimos: "pensamento estratégico”, “pensamento militar”, “mentalidade militar” e "pensamento dos militares".

O “pensamento estratégico” poderia ser definido como sendo aquele ligado a concepções mais amplas que podem ser ou não de natureza militar, mas que envolvem sempre questões consideradas “estratégicas” pelos atores em interação, condicionando, assim, padrões de comportamento. Compreendedefinição de objetivos, antecipação de movimentos, planejamento delongo prazo, cálculo de custo-benefício, manejo de informação, tomada de decisões e graus variados de incerteza em relações complexas de conflito, competição ou negociação ${ }^{4}$. Pensar estrategicamente, portanto, não é necessariamente prerrogativa do profissional militar, já que tal exercício pode servir tanto para a política de um Estado, como para uma organização, empresa ou indivíduo.

A idéia de “pensamento militar”, por sua vez, pode ser tomada em sentido estrito e aplicada especificamente à estratégia e à tática militares, ou àquilo que se convenciona chamar de "arte da guerra”. É o caso, por exemplo, da doutrina militar, entendida como um "conjunto de princípios e enunciados que servem de fundamento para o uso do poder nacional”, pelos quais se sistematiza e se coordena o emprego conjunto das forças singulares de um Estado. Tratase de como organizar, adestrar e preparar o sistema militar para cada hipótese de guerra ${ }^{5}$. O "pensamento militar" se refere a preocupações profissionais tipicamente militares, tais como estrutura da corporação, planejamento e 
comando, problemas logísticos, técnicas de combate, modalidades e formas de emprego das Forças Armadas.

"Pensamento militar", desse modo, não deve ser confundido com "mentalidade militar" (military mind), que se relaciona à visão que os militares têm do mundo, aí implícita a adesão a um sistema de valores característico e a existência de uma ética própria decorrente da natureza da profissão. São diversos os estudos nos campos da sociologia e da ciência política referentes aos padrões de mentalidade construídos ao longo da carreira militar, em função de peculiaridades inerentes à vida da caserna ${ }^{6}$. Anoção de ethos militar se constrói a partir da constatação de que os exércitos profissionais permanentes possuem objetivos, símbolos e distintivos que são nacionais, mas a estrutura básica e os princípios de organização que lhes servem de fundamento são similares de um país a outro ${ }^{7}$.

Adefinição aplicável aqui ao “pensamento dosmilitares”, por fim,éa amais singela, pois se refere às opiniões e concepções elaboradas pelos militares em assuntos específicos. Neste caso, pode haver um pensamento dos militares em matéria de economia, política, saúde e educação, ou sobre temas como a integração nacional, os meios de comunicação, a cultura, e assim por diante. Quando se faz referência neste artigo ao “pensamento dos militares”, como já foi dito, tem-se em mente posições e análises de militares brasileiros na área de relações internacionais e Política Externa.

É preciso reconhecer, porém, que a tarefa de tentar tipificar o pensamento da corporação militar, em qualquer assunto que seja, repousa sempre em bases precárias e aproximativas da média existente entre os diversos grupos que compõem a instituição, por si mesma complexa e politicamente heterogênea ${ }^{8}$.

A importância de se analisar o pensamento desse segmento da sociedade brasileira tem como pressuposto o vínculo necessário existente entre os militares e a política internacional. A conduta externa de um país, hoje, ainda se dá em um contexto em que as questões de segurança e defesa se apresentam como elementos constitutivos do jogo político-diplomático, ou seja, o aspecto estratégicomilitar das relações internacionais contemporâneas, tanto quanto o econômico, é parte integrante do elenco de forças que influencia as decisões de Política Externa de cada unidade estatal. À noção de que, na sua origem, os exércitos foram criados ante a ameaça de conflito com unidades externas, some-se o fato de que o estabelecimento de Forças Armadas regulares, no âmbito do Estado, introduziu novo ator interno no processo de formulação de políticas e de tomada de decisões governamentais, o qual pode vir a desempenhar graus variados de autonomia ou de influência. Em conseqüência, pode-se chegar a ter, em casos extremos, um 
relacionamento interdependente entre a Política Externa de um Estado e o pensamento da instituição militar, ocasião em que ambos severiam aglutinados em uma só realidade ${ }^{9}$.

Tomando, em princípio, apenas a finalidade primeira eúltima de qualquer força armada, que seria o preparo para a guerra, observa-se desde logo que a elaboração de uma doutrina para eventual uso dessa força está condicionada às conjunturas nacional (poder mobilizável e capacidade acumulada do país) e internacional (percepção da ameaça, eventuais aliados e inimigos). Em outras palavras, para o cumprimento específico da missão estritamente profissional que lhes é destinada, os militares precisam avaliar continuamente as condições prevalecentes no meio internacional e os possíveis cenários estratégicos onde o emprego do poder militar do país possa vir a ser requerido para a defesa nacional.

No caso brasileiro, o vínculo militares-política internacional é particularmente visível no período 1964-1984, mas possui antecedentes históricos ligados à presença dos militares na política. Mucio Piragibe Bakker assinala, a propósito, que a liquidação dos problemas de fronteira no princípio deste século, entre outros fatores, teria servido para enfraquecer o profissionalismo clássico e aumentar a preocupação (sobretudo no Exército) com a evolução interna do país ${ }^{10}$. Paradoxalmente, o maior envolvimento com os assuntos domésticos gerou interesse também pela Política Externa, na medida em que as disputas políticas em torno do controle do Estado tinham reflexos nas opções de inserção internacional do país e vice-versa.

A presença dos militares na frente externa se verifica, ainda, em termos de atuação das Forças Armadas em áreas temáticas de interesse estratégico, como as de armamentos, pesquisa espacial, energia nuclear e informática, seja na formulação de políticas (influenciando ou orientando), seja no aspecto prático e operacional. Podem ser lembradas também as missões militares formais e informais, permanentes ou temporárias, o serviço de informações e o papel dos adidos militares no exterior, além da participação em Operações de Paz das Nações Unidas ${ }^{11}$.

\section{Limitações da interpretação crítica tradicional}

Com relação à análise do pensamento dos militares, da leitura da bibliografia disponível sobre o assunto detecta-se número não desprezível de trabalhos que convergem para uma interpretação baseada na hegemonia norteamericana como fator explicativo do tipo de produção intelectual dos militares 
brasileiros no período em tela. A ela pode-se chamar de interpretação crítica tradicional.

Essa tentativa de interpretação sustenta grosso modo que a Doutrina de Segurança Nacional (DSN), nascida nos Estados Unidos, no contexto da Guerra Fria e do antagonismo Leste-Oeste, teria sido simplesmente "exportada" para o Brasil e demais países latino-americanos, ao passo que a Escola Superior de Guerra (ESG), inspirada no National War College, teria sido o resultado de entendimentos diretos entre militares brasileiros que participaram da Força Expedicionária Brasileira (FEB), durante a Segunda Guerra Mundial, e seus colegas norte-americanos. Com isso, o conceito de national security, adotado nas escolas militares no Brasil, juntamente com a ideologia anticomunista e a estratégia de contenção do poderio soviético (dominante em um mundo de confrontação global bipolar ou, como se dizia, de "guerra total"), teria fundamentado, a partir de 1964, as políticas estratégicas do novo regime e, na linha ideológica do Brasil como "baluarte do Ocidente”, o padrão de ação diplomática daí decorrente.

Os militares teriam feito o casamento entre a Doutrina de Segurança Nacional e a geopolítica (anterior à DSN), fornecendo, assim, o fundamento “científico" necessário à doutrina e uma ideologia legitimadora para a consecução dos objetivos de um Estado autoritário e militarista. Os geopolíticos seriam, portanto, os grandes teóricos do regime, como o teriam sido os Generais Golbery do Couto e Silva e, em menor grau, Carlos de Meira Mattos. Tendo em vista o novo status de satélite privilegiado dos Estados Unidos na região, o Brasil participaria do sistema de defesa ocidental contra o comunismo internacional, enquanto, em troca, poderia dedicar-se a exercer missão subimperial na América do Sul, com a conivência do "grande aliado do Norte”. O expansionismo típico de "potência emergente" estaria plenamente abalizado pelos ditames geopolíticos, que o advogariam como conseqüência inelutável do destino de grandeza que a geografia havia reservado ao país ${ }^{12}$.

Trata-se de interpretação-padrão bastante abrangente que, embora levante alguns pontos pertinentes, falha quando superestima a influência norte-americana e tende ao determinismo e à generalização simplista. Pouca atenção se dá às origens nacionais do pensamento dos militares, à diversidade das forças políticas existentes dentro das Forças Armadas, às diferenças de orientação de Governo a Governo ou à autonomia das decisões brasileiras no que se refere a relações exteriores. Procura-se explicar a Política Externa dos Governos militares à luz dos preceitos geopolíticos escritos por número restrito de autores, aos quais seria atribuída a capacidade de representar a totalidade do pensamento do oficialato. 
A própria evolução histórica da Política Exterior do Brasil demonstra a dificuldade que há em se aceitar integralmente a interpretação crítica tradicional. Mesmo durante o Governo Castelo Branco (1964-67), considerado o paradigma mais acabado da interpretação, não há registro de que os Estados Unidos tivessem dado qualquer espécie de endosso ao Brasil para o exercício de uma suposta missão subimperialista. A análise da historiografia sobre a Política Externa também não corrobora a idéia de que o Brasil teria desempenhado o papel de país-chave no continente nem que teria desfrutado de "vantagens" como aliado preferencial da potência hegemônica ${ }^{13}$. No quadro global, a América Latina permanecia como área de interesse estratégico marginal e zona de influência natural norte-americana. Os Estados Unidos nunca ofereceram "recompensas" pelo apoio manifestado pelo Brasil, pois, como bem assinalou Carlos Estevam Martins, os capitais não afluíram em quantidade suficiente, a ajuda de programas de assistência (como a Aliança para o Progresso e a USAID) foi muito limitada, e a tecnologia continuou guardada a sete chaves ${ }^{14}$.

Conforme demonstrou Alfred Stepan, a tomada do poder em 1964 resultou, em larga medida, de uma dinâmica política interna própria, impulsionada sobretudo por grupos do Exército, desejosos de implementar na prática o projeto de nação maturado na ESG ${ }^{15}$. Embora ainda esteja para ser feito um julgamento definitivo da "correção de rumos” da diplomacia de Castelo Branco, pode-se dizer que a necessidade, naquele momento, de negar o discurso do Governo anterior, bem como a conjugação de interesses com os Estados Unidos, originaram, por posição de conveniência, o ocidentalismo radical da "Política Externa interdependente”. O “alinhamento automático” do liberalismo associado, todavia, não resistiria às forças históricas que apontavam em outra direção e, superada a fase dos extremismos, recolheu-se ao cemitério das ideologias ${ }^{16}$.

A partir de 1968, com a “diplomacia da prosperidade” do Governo Costa e Silva e a ascensão ao poder de segmentos nacionalistas entre os militares, começam a ficar mais nítidas diferenças de orientação entre o Brasil e os Estados Unidos, culminando, em 1977, com o rompimento do Acordo Militar durante o Governo Geisel. O crescimento econômico brasileiro e a busca de maior autonomia para o país entravam em choque com a posição norteamericana de não permitir o surgimento de nova potência na sua esfera de influência, especialmente se esta dispusesse de suficiente independência para poder optar, em áreas sensíveis (como a da energia nuclear), por outros parceiros que não os Estados Unidos. O “pragmatismo responsável” e a estratégia de diversificação de parcerias ilustram bem esse aspecto ${ }^{17}$. 
Quanto à ESG e à Doutrina de Segurança Nacional, vários autores já se encarregaram de mostrar que houve, de fato, influência norte-americana, inclusive na forma de envio de missão especial para auxiliar no estabelecimento da Escola, criada em 1949. No entanto, como adverte Eliézer Rizzo de Oliveira, "há que se evitar atribuir aos militares da ESG a simples cópia das doutrinas americanas” ${ }^{18}$. As idéias norte-americanas foram aceitas porque os militares já concordavam antes com seus pressupostos e puderam, dessa forma, reformulálas e adequá-las à sua própria percepção dos problemas de desenvolvimento e de segurança do país. Alfred Stepan assinala, a respeito, que desde o princípio a ESG era anticomunista e estava empenhada na Guerra Fria. Já que o comunismo era o inimigo, “os Estados Unidos, sendo o principal país anticomunista, eram um aliado natural” 19 .

Raízes do conceito de segurança nacional foram encontradas no pensamento de Góes Monteiro, militar que participou da Revolução de 1930 e foi colaborador direto de Getúlio Vargas durante o Estado Novo ${ }^{20}$. Porta-voz das aspirações de renovação nacional do movimento tenentista, Góes Monteiro preconizava, entre outras coisas, o nacionalismo econômico e um Estado forte para a implantação de indústrias nacionais de base e exploração autônoma das riquezas do subsolo, única maneira, segundo ele, de construir a verdadeira segurança da nação e de fazer valer a "política do Exército"21. A capacidade industrial do país confundir-se-ia com a capacidade militar, e a forma de viabilizar esse projeto estaria na ordem e na disciplina, em conformidade com os princípios da organização militar. O anticomunismo, que cresceu consideravelmente depois da chamada Intentona Comunista de 1935, além de unir a tropa, justificava também medidas de exceção internamente, pois, no entender de Góes Monteiro, a defesa nacional seria o resultado de uma política de desenvolvimento que implicaria "uma estratégia global de rígida contenção das forças políticas em luta e disciplina social22",

Edmundo Campos Coelho afirma que a doutrina de Góes Monteiro antecipou em mais de vinte anos a DSN: “A nossa tese é, na verdade, a de que o pensamento de Góes Monteiro foi simplesmente retomado e reelaborado em função de uma nova conjuntura ${ }^{23}$."

Também são citados, como fontes nacionais da doutrina da ESG, os pensamentos deAlberto Torres e Oliveira Vianna ${ }^{24} \mathrm{e}$, como fonte não-americana, as idéias de guerra total do alemão Erick von Lüdendorff ${ }^{25}$.

No que se refereà geopolítica, sua influência nas decisões governamentais nãodeve serigualmentesuperdimensionada. ShiguenoliMiyamoto defende, em denso e exaustivo trabalho sobre a questão, quepelo ingresso maciço de capital estrangeiro 
e o tipo de desenvolvimento associado, observados após 1964, nãose pode dizer que a Política Externa brasileira tenhasido formuladasegundo as teorias geopolíticas, mas sim em função dos interesses político-econômicos em jogo ${ }^{26}$. Miyamoto analisou tópicosespecíficos que foram objeto de estudos porparte dos geopolíticosbrasileiros (a mudança da capital federal, a questão das fronteiras, a redivisão territorial, a geopolítica dos transportes e os corredores de exportação, a projeção do Brasil na América do Sul, a interiorização e a integração nacional, entre outros) e demonstrou as contradições entre o discurso geopolítico, e suas propostas, com o que de fato ocorreu. Os policy-makers responsáveis pela conduta externa do Brasil ignoravam os estudos geopolíticos e suas motivações eram fundamentalmente diversas daquelas existentes nesses mesmos estudos ${ }^{27}$.

As obras de Golbery do Couto e Silva e Meira Mattos tiveram impacto maior e foram mais debatidas no exterior do que no Brasil, sobretudo nos países vizinhos, em virtude das referências explícitas que eram feitas a "projeções de poder" no plano regional e ao "destino" do Brasil como "grande potência mundial”28. A interpretação crítica tradicional toma esses autores como modelos e referencial válido para caracterizar todo o pensamento dos militares brasileiros, em especial Golbery do Couto e Silva, suposição que deveria ser qualificada, conforme assinala Ubiratan de Macedo:

“Do General Golbery, muito mais relevante é a influência de seu livro sobre Planejamento Estratégico do que seus estudos geopolíticos, estes considerados com curiosidade e simpatia, mas sem serem incorporados ao ideário oficial da Escola [ESG], ao contrário do sucedido com o outro livro ${ }^{29}$.

\section{A política internacional à luz da doutrina}

Para fins de compreensão do pensamento dos militares, a doutrina assume considerável importância pelo fato de ser elaborada a partir de estudos realizados por oficiais e discutida ao longo do tempo nas Escolas de Alto Comando de cada uma das forças singulares, em um processo eminentemente coletivo. A ESG, vinculada diretamente ao Estado-Maior das Forças Armadas(EMFA), representou, desde que foi criada, foro privilegiado para a formulação doutrinária conjunta entre o Exército, a Marinha e a Aeronáutica. Adoutrina da ESG, nesse sentido, reflete o grau de consenso relativo atingido entre as forças no que concerne à definição de seus princípios e fundamentos para a ação.

Um traço peculiar à doutrina da ESG, particularmente após 1961, foi o da introspecção estratégica, provocada pela lógica de guerra interna inerente à 
DSN. Os estudos sobre relações internacionais passaram a um plano secundário, ou eram mesmo quase inexistentes, a não ser quando se referiam especificamente à ameaça hipotética oriunda dos países comunistas ${ }^{30}$. A preocupação com a "guerra revolucionária” e a “segurança interna” trouxe para o âmbito doméstico a linguagem, o discurso e as concepções utilizadas comumente para o estudo e o entendimento do meio internacional, como observa Antonio Carlos Pereira: “Os conceitos usados pela Doutrina de Segurança Nacional (segurança, podernacional, estratégia, objetivos nacionais, fronteiras ideológicas, guerra ideológica, guerra subversiva, etc.) foram tomados emprestados da política internacional. Aplicados ao plano interno, levaram à transformação do adversário em inimigo ${ }^{31}$."

No Manual Básico da ESG, de 1977-1978, por exemplo, das seis seções que compunham o capítulo III, cinco eram dedicadas aos conceitos de segurança nacional, guerra contemporânea, guerra revolucionária comunista, operações psicológicas e segurança interna, e apenas uma tratava de segurança externa ${ }^{32}$.

Com o processo de redemocratização e o início da Nova República, em 1985, diminuiu a ênfase nos aspectos internos da guerra não-clássica e muitos itens que tratavam desse assunto desapareceram da doutrina. A estrutura básica e a divisão dos temas, contudo, permaneceram praticamente idênticas até 1989, último ano coberto na pesquisa que originou este artigo. Houve somente alterações tópicas, quanto à forma de apresentação e ao conteúdo de alguns itens específicos, tais como justiça social e ciência e tecnologia. Qual era, portanto, o tratamento dado pela doutrina à política internacional, à Política Externa e ao papel da diplomacia?

Para a doutrina, a comunidade internacional estaria organizada em um sistema de unidades políticas autônomas (Estados soberanos), que não admitiriam qualquer interferência na consecução de seus objetivos nacionais. O Estado, representando a nação ao projetar sua ação no âmbito externo, encontraria um universo formadoporunidadesigualmente capazes de tomardecisões independentes, apoiadas em seus respectivos poderes nacionais, ocasionando o conflito de interesses e de aspirações ${ }^{33}$ :

“Assim, no terreno das influências recíprocas, cada nação busca conquistar e manter seus objetivos ou preservar seus legítimos interesses, surgindo, clara ou veladamente, a tentativa de estabelecimento de hegemonia, o que de pronto contribui para a existência de áreas de cooperação como para o surgimento ou exacerbação de focos de conflitos ${ }^{34}$."

O direito internacional, nascido da necessidade de limitar ou de ordenar esses conflitos, não estaria sendo capaz de resolver o problema da segurança para os Estados em face dos antagonismos existentes nas relações internacionais. 
A História mostraria que a paz, a guerra, a cooperação, a dependência, as alianças e os blocos de defesa, recebem interpretações diversas por parte desses mesmos Estados ${ }^{35}$. Juridicamente, as relações seriam baseadas na igualdade e na reciprocidade, mas a realidade política seria bem diferente: os poderes nacionais e as estaturas estratégicas dos Estados desempenhariam papel preponderante. Continua a doutrina: "Em conseqüência, o sistema internacional apresenta estrutura hierárquica bem caracterizada, dispondo-se os componentes de maior poder e estatura no centro deste sistema, ao passo que os mais fracos se encontram na sua periferia $^{36}$."

Cada Estado procuraria fortalecer-se a seu modo e adequar sua inserção no mundo de acordo com sua posição geográfica e acervo histórico-cultural. A neutralidade, o isolamento, o não-alinhamento, a adesão a tratados e alianças, 0 ingresso em sistemas de segurança coletiva, seriam algumas da alternativas possíveis para a sobrevivência em um mundo incerto. Entretanto, a busca de soluções externas para reforço de poder e de segurança (aparentemente a solução mais fácil e menos dispendiosa) seria sempre precária e instável, por depender da evolução da conjuntura internacional e não fornecer garantias de que os compromissos sejam cumpridos, além de enfraquecer o controle nacional sobre decisões vitais ${ }^{37}$. Sendo o problema básico das relações internacionais, segundo a doutrina, a busca e a manutenção do poder, uma política de segurança externa deveria partir da identificação dos objetivos nacionais permanentes que tivessem relação com a integridade do território e a manutenção da capacidade do Estado de tomar decisões independentes. Conclui-se que: "Embora não represente um imperativo universal, só um Poder Nacional, preparado e aplicado por uma Estratégia de Segurança Externa realista, oportuna e flexível, representa efetivamente o alicerce de garantia necessário a uma nação ${ }^{38}$."

Fica claro que, para atender ao imperativo da segurança, somente o fortalecimento do poder nacional preencheria os requisitos de confiabilidade desejados, a fim de que o Estado verdadeiramente independente tivesse como se garantir pela autonomia dos meios e das capacidades. O poder nacional, cerne da matriz doutrinária, estaria estruturado nas suas quatro expressões: política, econômica, militar e psicossocial. Quando o poder potencial mobilizável de um Estado não fosse suficiente para garantir sua segurança pelo esforço autônomo, a diplomacia teria de suprir essa carência, pela negociação e por meio de medidas persuasivas destinadas a desestimular ou minimizar rivalidades: "A necessidade de dinamizar a Diplomacia torna-se imperiosa quando o grau de desenvolvimento nacional não permite [ao Estado] aparelhar-se com meios de defesa suficientemente poderosos para atender às Hipóteses de Guerra ${ }^{39}$.” 
Tendo em vista a realidade internacional na qual o Estado se projeta, uma Política Externa voltada para a conquista e a manutenção dos objetivos nacionais levaria em consideração os acordos, tratados, pactos e alianças formalmente estabelecidos, ainda que a História comproveque esses instrumentos internacionais sejam, às vezes, descumpridos. É inegável, de acordo com a doutrina, que a existência de determinadas regras de convivência tem servido como fator inibidor de uma ruptura brusca do status quo (pelo uso da coerção física) e como amortecedor de interesses contrários à estabilidade internacional. A diplomacia utilizaria métodos graduais e flexíveis de maneira a só aceitar o emprego do poder militar como último recurso ${ }^{40}$.

Pelo exposto até aqui, conclui-se que a visão teórica do meio internacional que prevalece na doutrina é aquela do realismo político clássico ${ }^{41}$. Embora não seja novidade que entre os militares sempre houve receptividade, na prática do ofício, à concepção realista da política internacional, parece de interesse registrar que sua incorporação formal à doutrina constitui indicativo de que, no plano conceitual, assume-se como fonte válida de conhecimento determinada teoria das relações internacionais, cujo consumo entre os militares traz implicações também para a Política Exterior do Brasil, como se verá a seguir.

\section{O pensamento dos militares e a Política Externa}

Em termos de produção intelectual dos militares no campo das relações internacionais, levantamento que fizemos em revistas e periódicos nacionais especializados, no período 1961-1989, indicou que alguns temas eram recorrentes em virtude de sua relevância estratégica ou militar para o Brasil, do ponto de vista das Forças Armadas: a questão das fronteiras (defesa, ocupação e presença); a Amazônia (gestão do território e defesa da soberania nacional contra a cobiça estrangeira); Atlântico Sul e Antártica (sobretudo em publicações da Marinha); Cone Sul (ênfase nas relações com a Argentina e perspectivas político-econômicas na sub-região); e, por fim, análises setoriais (temática e geograficamente), do tipo “conhecer o inimigo", sobre os avanços do comunismo internacional (Política Externa dos países socialistas, avaliações do poderio soviético, chinês, cubano, etc.). Com exceção do último caso, relativo à conjuntura vivida naqueles tempos, a ênfase dos estudos dos militares recai sobre o entorno geográfico do país e seus pontos críticos de contato-atrito com o mundo exterior.

Puderam ser encontrados, também, textos esparsos, não especificamente sobre relações internacionais, mas correlatos nas áreas de administração, economia, finanças, ciência e tecnologia, organização, técnicas e táticas militares ${ }^{42}$. 
Quanto a influências recebidas de autores estrangeiros, o levantamento mostrou que dois nomes sobressaíam na área de relações internacionais: Hans J. Morgenthau e Raymond Aron. Pertencentes à escola clássica do realismo, ambos eram freqüentemente citados ou incluídos em bibliografias de textos escritos por oficiais. Na área de estratégia, mereciam destaque: Basil H. Liddell Hart, André Beaufre e os eternos Zun Tzu e Karl von Clausewitz. Entre geopolíticos, eram feitas referências aos teóricos Friederich Ratzel e Juan Rudolph Kjéllen; a Alfred T. Mahan (poder naval); Halford Mackinder, Nicholas J. Spykman e Karl N. Haushofer (poder terrestre); e Giulio Douhet e Alexander Seversky (poder aéreo). Em trabalhos sobretudo de natureza doutrinária eram comuns referências a alguns autores da área da ciência política: Robert Dahl, David Easton, Karl Deutsch e Harold Lasswell. Conviria ressaltar, ainda, o impacto que teve entre os militares o estudo de Ray S. Cline sobre "avaliação do poder mundial”, em 1975, onde o Brasil era então colocado em sexto lugar, em termos de “poder perceptível”, entre as grandes potências mundiais ${ }^{43}$.

Em estudo realizado por Maria Regina Soares de Lima e Zairo B. Cheibub, em 1983, constatou-se que as questões relacionadas aos enfoques militares eram veiculadas quase que exclusivamente em revistas militares, tanto profissionais quanto de divulgação. Em comparação com as revistas da área de ciências sociais, as publicações militares abrigavam: 91,6\% das formulações geopolíticas; 72,1\% das análises estratégico-militares; 77,3\% dos artigos sobre guerras e conflitos; e 85,6\% quando o assunto era a Política Externa dos países socialistas $^{44}$. Os militares tendem a produzir reflexões mais voltadas para o ângulo estratégico-militar da política internacional, o que é natural. Estudos específicos sobre Política Externa brasileira e diplomacia, porém, são raros ${ }^{45}$.

Admitindo, como se viu, o peso do realismo políticona visão militar domeio internacional, quais seriam as conseqüências advindas para a Política Externa? Os militares almejavam, para o Brasil, uma posição de importância no quadro mundial, consentânea com o potencial de um país de dimensões continentais, através da qual o Brasil deixaria de ser espectador e passaria a ter voz ativa no concerto das nações. O robustecimento do poder nacional permitiria ao Estado brasileiro fazerse forte o bastante para, em um mundo dominado pela lógica fria dos interesses, abrir seu próprio caminho visando à criação de um novo centro de poder independente na América do Sul.

A “construção da potência”, para utilizar a expressão de Geraldo Lesbat Cavagnari, passou a ser preocupação constante no pensamento dos militares, na expectativa de que a ascensão do Brasil a níveis superiores da hierarquia internacional de poder tivesse como corolário a ampliação das atribuições do poder 
militar na defesa de interesses nacionais além-fronteiras ${ }^{46}$. A noção realista de potência, ressalte-se, possuía enraizamento profundo no nacionalismo dos militares e não era de modo algum apanágio exclusivo das obras magnas da geopolítica, ainda que freqüentasse com desenvoltura aqueles textos.

Com a Revolução Cubana, e sobretudo após 1961 (ano da criação da Escola das Américas, no Panamá), a estratégia norte-americana para a América Latina havia passado a privilegiar o tema da "guerra revolucionária" e do "inimigo interno", por intermédio de programas de segurança voltados para o interior do continente e do envio de materiais leves e equipamento militar antiguerrilha. Em caso de ameaça externa (uma hipotética iniciativa de guerra por parte da União Soviética), os Estados Unidos assumiriam a responsabilidade da defesa continental, sendo este o motivo por que os exércitos latino-americanos deveriam voltar-se prioritariamente à segurança interna e à ação cívico-social ${ }^{47}$.

Os militares brasileiros estavam conscientes de que a defesa da soberania nacional não era tarefa a ser delegada a outro Estado e que a emergência de novo centro de poder político não poderia admitir a subordinação estratégica ad infinitum ao poder hegemônico. Aluta nacionalista pela elevação do prestígio internacional do país, por conseguinte, teria de ser perseguida mediante a autonomia do desenvolvimento. As dificuldades criadas pelos Estados Unidos para a cessão de material bélico moderno e sofisticado, na década de 1970, levaram o Brasil a buscar ativamente fontes européias de armamentos e tecnologia (o Acordo Nuclear com a RFA, em 1975, foi o exemplo mais claro), visto que o estabelecimento de um sistema de segurança mais independente pressupunha maior grau de autonomia na fabricação de armas e na posse de conhecimento para gerá-las.

Nesse sentido, com a finalidade de descrever o conjunto das políticas estratégicas implementadas pelos Governos militares, Clóvis Brigagão e Domício Proença Jr. identificaram um “tripé” industrial-tecnológico do poder brasileiro, ou seja, a indústria de armamentos, a informática e a nuclearização teriam sido os “três componentes essenciais do empenho brasileiro no sentido de adquirir um poderio autônomo regional e internacional digno de crédito”48. Dado o papel preponderante do Estado no tipo de modernização pretendida, não é de todo incorreto afirmar-se que tal processo se constituiu, segundo a observação de Max Manwaring sobre as elites político-militares brasileiras, em uma tentativa de “construção do Brasil à sua própria imagem”, a qual recebeu posteriormente o nome de nacional-desenvolvimentismo ${ }^{49}$.

O ano de 1977 representou, para os militares, marco conceitual na via da autonomia estratégica, visto que, na prática, o Acordo Militar de 1952 com os Estados Unidos já era inoperante ${ }^{50}$. A nacionalização dos meios, a redução da 
dependência e das vulnerabilidades nacionais, maior liberdade de manobra logística e operacional, eram todas reivindicações antigas dos militares com vistas a impedir a transferência dos centros de decisão para o estrangeiro e a garantir a soberania plena do país em todos os campos do desenvolvimento. A Guerra das Malvinas, em 1982, com a demonstração de superioridade tecnológica da potência extracontinental, foi prova cabal da necessidade urgente de modernização das Forças Armadas brasileiras e de programas de reequipamento em bases nacionais ${ }^{51}$.

Claro está que a superação autonomista da dependência, preconizada pelos militares, devia ser buscada em termos de integração da economia nacional no capitalismo mundial, e não fora dele, como levavam a pensar as correntes mais radicais da teoria da dependência, que desembocavam, em última análise, na via socialista. O anticomunismo arraigado entre os militares e a opção estratégica pelo Ocidente, aliás, não poderiam sugerir curso de ação diferente.

Com o propósito de construir a potência e de elevar o prestígio nacional, porém, o nacionalismo dos militares foi pragmático em seu aspecto operacional. Tal pragmatismo diplomático, necessário a fim de otimizar a inserção econômica do país, casava-se bem com o realismo e chegava às vezes a ter precedência sobre considerações ideológicas anticomunistas, como já o comprovam os estudos sobre a Política Externa brasileira no período em tela. Bastaria lembrar que, mesmo durante o Governo Castelo Branco, quando haveria de se supor maior animosidade em relação aos países socialistas, não se abriu mão das possibilidades de comércio e de cooperação econômica com o bloco liderado pela União Soviética ${ }^{52}$.

A partir da redemocratização do país, foram surgindo sinais de que as Forças Armadas necessitavam caminhar em direção a uma revisão dos conceitos fundamentais que nortearam suas idéias, de modo mais ou menos perene, desde o fim da Segunda Guerra Mundial. Os riscos de esterilização do conhecimento e de dogmatismo ideológico, somados à ausência de debate, reforçavam entre os próprios militares essa conviç̧ão ${ }^{53}$. Alguns fatores políticos também contribuíram para a consolidação da tendência à mudança: a distensão internacional Leste-Oeste e as transformações verificadas na União Soviética, sob o impacto da perestroika de Michail Gorbachev; a volta dos regimes democráticos no continente sul-americano e o incremento das relações de cooperação e de integração econômica entre o Brasil e seus vizinhos do Cone Sul, notadamente a Argentina; o novo perfil de segurança do Brasil, que havia desenvolvido uma indústria bélica nacional e uma capacidade econômica acima da média dos países considerados do "Terceiro Mundo”; e, no final da década de 1980, a crise do "socialismo real" 54 . 
De acordo com Armando Amorim Ferreira Vidigal, três hipóteses de guerra haviam dominado o pensamento militar brasileiro desde os anos 1960: a) o envolvimento em uma guerra extracontinental, como força de apoio ao esforço dos Estados Unidos e demais potências ocidentais, em caso de deflagração de conflito mundial com o bloco comunista; b) conflito regional com a Argentina ou com uma aliança formada por países hispânicos limítrofes; c) guerra revolucionária e anti-guerrilha. Essas três hipóteses, considerando os fatores mencionados no parágrafo acima, haviam perdido sua substância e não correspondiam mais à realidade externa na qual se inseria o Brasil. O conflito global dificilmente ocorreria em um futuro previsível, a cooperação regional (inclusive militar) já era um dado concreto, e o inimigo interno havia desaparecido. O resultado disso foi a perda dos referenciais que antes orientavam o pensamento e a ação dos militares, que teriam entrado, no dizer de Armando Vidigal, em "crise existencial”, provocada pela ausência de objetivos e metas plausíveis ${ }^{55}$.

Em 1988, o Almirante Mário César Flores alertava para a necessidade de renovação do pensamento e postulava a redefinição dos antigos valores e conceitos à luz da nova realidade que se fazia presente. Conclamava-se, então, a sociedade para que participasse do debate que se abria sobre o papel das Forças Armadas: “Conviria proporcionar aos cursos da ESG, pelo menos ao mais alto, uma orientação que servisse mais para estimular o pensamento do que para fazer crer em certezas. Conviria também aumentar naquela Escola o intercâmbio (já existente)como mundo político, diplomático, administrativo, científico eacadêmico, discutindo-se (...) e explorando-se a prospecção, com o apoio em instituições e pessoas aptas para tanto ${ }^{56}$."

Com diagnóstico similar, em 1989, Armando Vidigal se unia às correntes reformistas, oriundas em um primeiro momento sobretudo da Marinha, e afirmava: "É imprescindível que a sociedade brasileira, que não se sente ameaçada do exterior, e, portanto, que considera irracional o emprego da força nas relações internacionais, seja conscientizada da importância fundamental das Forças Armadas para o progresso do país. Esta conscientização resultará, inter alia, da participação da sociedade no debate que estamos convocando para o estabelecimento de uma nova concepção estratégica para o país. Sem esta efetiva participação, nenhuma concepção será válida ou eficaz ${ }^{57}$.”

A tarefa de rever concepções e doutrinas no pós-Guerra Fria constitui assunto em evolução entre militares e segmentos da sociedade engajados no debate estratégico, cuja apreciação, até os dias atuais, escapa aos limites deste artigo. Caberia apenas recordar, entre os progressos visíveis já alcançados recentemente, a adoção do documento de Política de Defesa Nacional, anunciado pelo Presidente 
da República, em novembro de 1996, o qual enumera princípios, define objetivose traça diretrizes para a atuação do Estado brasileiro na área de defesa.

\section{Conclusão}

Tomando como referência apenas as abordagens distintas daquelas usualmente praticadas no universo norte-americano da pesquisa em relações internacionais, a geopolítica é considerada uma das contribuições teóricas mais significativas daAmérica do Sulà disciplina (a outra seria a teoria da dependência), embora não necessariamente original ou analiticamente consistente, dada a complexidade de fatores envolvidos na dinâmica internacional, além do exclusivamente geográfico ${ }^{58}$. No entanto, élícito afirmar que, no pensamento dos militares entre 1961 e 1989, como se tentou mostrar, o paradigma realista exerceu influência muito mais marcante, em matéria de fundamento teórico para a compreensão da política internacional, do que a geopolítica.

Em termos de Política Externa, a geopolítica tampouco encontrou guarida seja no discurso seja na prática da diplomacia brasileira. Com as devidas ressalvas de ênfase, variações e inflexões de política, pode-se dizer que o pensamento político internacional dos militares esteve sempre muito mais ligado ao projeto nacional-desenvolvimentista, que norteou as grandes linhas da Política Exterior até o fim da década de 1980, do que com o receituário geopolítico ou o próprio liberalismo associado, restrito a 1964-67. O que poderia haver de substância na interpretação crítica tradicional, desse modo, não se aplica à Política Externa. Os traços de nacionalismo, autonomia e pragmatismo, presentes no pensamento dos militares, se confundiram com a própria diplomacia e se constituíram, na época, em fator de elevado consenso interno.

O ponto de diferença com a visão de outros segmentos da sociedade brasileira, à parte as críticas de "terceiro-mundismo" provenientes de setores liberais da direita, esteve na maior ou menor determinação dos militares na construção da potência como solução para aumentar o prestígio nacional, a qual adquiriu contornos triunfalistas em certos momentos. Os pressupostos realistas, levados às suas últimas conseqüências, induziam a supor que para um país periférico ter voz ativa na política mundial, entendida em sua forma mais crua de "política de poder", seria preciso que este se instrumentalizasse dos meios (inclusivemilitares) para participardo “divertimento" das relações internacionais.

O esgotamento do modelo nacional-desenvolvimentista coincidiu com o fim da Guerra Fria e atingiu o cerne do pensamento não só dos militares, mas de 
todos os segmentos que então se dedicavam à reflexão sobre a inserção internacional do país. No contexto da globalização, as antigas dicotomias “associação versus autonomia" e "liberalismo versus nacionalismo" perderam o sentido. Nesta nova fase de investigação intelectual em andamento, já se pode antever o fim da geopolítica como instrumento de análise crível e a aceitação crescente de que há, pelo menos, fortes restrições a serem feitas ao uso do realismo político como fundamento da ação diplomática de um país como o Brasil, em especial nas suas versões mais conservadoras, estatocêntricas, elitistas e dogmáticas.

Dentro da perspectiva de consolidação de uma cultura estratégica no Brasil, com respaldo civil, caberia observar nos próximos anos a evolução do pensamento brasileiro em direçãoauma (quiçádesejável, porém deconsecuçãoreconhecidamente difícil) reflexão teórica pós-Guerra Fria, que tome por base a missão dos militares em um país pacífico, desnuclearizado, sem pretensões hegemônicas, com ativa diplomacia de paz e inserção regional múltipla, o qual, por sua profundidade geoestratégica, necessita também possuir capacidade de auto-proteção e de resposta a ameaças, mediante uma força mínima de dissuasão defensiva.

Abril de 1997

\section{Notas}

1 Amado Luiz Cervo (org.), O desafio internacional: a Política Exterior do Brasil de 1930 a nossos dias. Brasília: EdUnB, 1994, p. 17; Gelson Fonseca Jr., “Estudos sobre Política Externa no Brasil: os tempos recentes (1950-1980)”, in Gelson Fonseca Jr. \& Valdemar Carneiro Leão (org.), Temas de Política Externa brasileira. Brasília: FUNAG/Ática, 1989, p. 275-283, p. 276. Ver também o importante artigo de Maria Regina Soares de Lima, "Enfoques analíticos de Política Exterior: el caso brasileño", in Roberto Russel (ed.), Enfoques teóricos y metodológicos para el estudio de la Política Exterior. Buenos Aires: RIAL/Grupo Editor Latinoamericano, 1992, pp. 53-83.

2 Esses três segmentos não são, evidentemente, os únicos a influir na formação do pensamento brasileiro em política internacional. Também devem ser lembrados, em maior ou menor grau, os empresários, os jornalistas, os parlamentares e os partidos políticos, a burocracia econômica governamental, os sindicatos, a comunidade técnico-científica, as ONGs, entre outros.

3 A pesquisa para a elaboração deste artigo foi originalmente realizada no âmbito do Grupo de Pesquisa em Relações Internacionais (GPRI), em 1991, formado então por alunos do curso de graduação em Relações Internacionais da Universidade de Brasília. As idéias aqui contidas são de exclusiva responsabilidade do autor e não refletem, necessariamente, a opinião da instituição à qual hoje se encontra vinculado. 
Dedico este artigo a todos os que passaram pelo GPRI e tiveram, naquela oportunidade, a experiência de tentar buscar pela base o constante aprimoramento da pesquisa universitária na área de relações internacionais.

4 Luciano Zajdsznajder, “Formação em pensamento estratégico”, São Paulo: Escola Brasileira de Administração Pública da Fundação Getúlio Vargas, mimeo, CA, 1990.

5 Francisco Ruas Santos (org.), Marechal Castelo Branco: seu pensamento militar (1946-1964). Rio de Janeiro: Imprensa do Exército, 1968, p. 244.

6 Sobre a “mentalidade militar” ver, entre outros: Samuel Huntington, The soldier and the state (Cambridge: Harvard University Press, 1957); Wright Mills, A elite do poder. Rio de Janeiro: Zahar, 1968; e Bengt Abrahamsson, Military professionalization and political power. Beverly Hills: Sage Publications, 1973; Alexandre de S. C. Barros, The Brazilian military professional socialization, political performance and state building. PhD Dissertation, University of Chicago, 1978.

7 Genaro Arriagada Herrera, El pensamiento político de los militares. Santiago: Centro de Investigaciones Socioeconómicas, Chile, s/d, p. 21.

8 Alfred Stepan, Os militares na política: as mudanças de padrões na vida brasileira. Rio de Janeiro: Artenova, 1975, p. 180.

9 Cf. Nicolas Boer, “A influência do pensamento militar na conduta política internacional”. Política e Estratégia. São Paulo: Editora Convívio, vol. I, n. 1, out./ dez.1983, pp. 144-127, p. 116.

10 Mucio Piragibe R. de Bakker, “O poder militar brasileiro: uma visão de suas particularidades”. Revista Brasileira de Política Internacional. Ano XXVII, 1984 (105-108), pp. 27-34, p. 29.

11 Ver, sobre o assunto, Alexandre Barros, "Problemas de transição democrática na frente militar: a definição do papel dos militares, a mudança da doutrina e a modernização do país”. Política e Estratégia, vol. VI, n. 2, abr./jun. 1988, pp. 206214, p. 211.

12 Há diferentes obras que adotam essa interpretação, no todo ou em parte. Ver, por exemplo, a título ilustrativo: Joseph Comblin, A ideologia da Segurança Nacional: o poder militar na América Latina. Rio de Janeiro: Civilização Brasileira, 1978; Maria Helena Moreira Alves, Estado e oposição no Brasil (1964-1984). Petrópolis: Vozes, 1989; Paul Schilling, O expansionismo brasileiro. São Paulo: Global, 1981; e Julio J. Chiavenato, Geopolítica: arma do fascismo. São Paulo: Global, 1981.

13 Ver Amado Luiz Cervo \& Clodoaldo Bueno, História da Política Exterior do Brasil. São Paulo: Ática, 1992, pp. 331-382.

14 Carlos Estevam Martins, “A evolução da Política Externa brasileira na década 196474”. Cadernos CEBRAP, 12, São Paulo, 1974, p. 67.

15 Cf. Alfred Stepan, Os militares na política, op. cit., p. 128.

16 É interessante notar que, mesmo em pleno fervor “revolucionário”, as limitações do “alinhamento automático” já podiam ser entrevistas no discurso diplomático. Nas palavras de Castelo Branco: "Reciprocamente, não devemos dar adesão prévia às atitudes de qualquer das grandes potências, pois que, na Política Externa destas, é 
necessário fazer a distinção entre os interesses básicos da preservação do sistema ocidental e os interesses específicos de uma grande potência. (...) Política Exterior independente, no mundo que se caracteriza cada vez mais pela interdependência dos problemas e dos interesses, significa que o Brasil deve ter seu próprio pensamento e sua própria ação. Sem subordinação a nenhum interessse estranho ao do Brasil.” Discurso do Presidente Castelo Branco na cerimônia do Dia do Diplomata, em 31 de julho de 1964, in MRE, A Política Exterior da Revolução brasileira - Discursos. Rio de Janeiro: Seção de Publicações, 1968, pp. 13-14.

17 Ver Antônio Carlos Moraes Lessa, “A estratégia de diversificação de parcerias no contexto do nacional-desenvolvimentismo (1974-1979)”. Revista Brasileira de Política Internacional, Ano 38, n. 1, 1995, pp. 24-39.

18 Eliézer Rizzo de Oliveira, “A Doutrina de Segurança Nacional: pensamento político e projeto estratégico”. Política e Estratégia, vol. VI, n. 2, abr./jun. 1988, pp. 233-246, p. 238.

19 Cf. Alfred Stepan, Os militares na política, op. cit., p. 132.

20 Consultar a respeito o livro de Edmundo Campos Coelho, Em busca de identidade: o Exército e a política na sociedade brasileira. Rio de Janeiro: Forense-Universitária, 1976.

21 Ver Pedro A. de Góes Monteiro, A Revolução de 30 e a finalidade política do Exército. Rio de Janeiro, Adersen Editores, 1932; e Leonardo Trevisan, O pensamento militar brasileiro. São Paulo: Global, Cadernos de Educação Política, 1985, pp. 30-43.

22 Edmundo C. Coelho, Em busca de identidade, op. cit., p. 114.

23 Idem, p. 105.

24 Cf. Shiguenoli Miyamoto, O pensamento geopolítico brasileiro (1920-1980). Dissertação de Mestrado, USP, 1981; e Ubiratan Borges de Macedo, “A Escola Superior de Guerra, sua ideologia e trânsito para a democracia”. Política e Estratégia, vol. VI, n. 2, abr./jun. 1988, pp. 215-222.

25 Antonio Carlos Pereira, “Aspectos totalizantes da Doutrina de Segurança Nacional”. Política e Estratégia, vol. VI, n. 2, abr./jun. 1988, pp. 252-271.

26 Cf. Shiguenoli Miyamoto, O pensamento geopolítico brasileiro, op. cit, e, muito especialmente, do mesmo autor, Do discurso triunfalista ao pragmatismo ecumênico: geopolítica e Política Externa brasileira pós-64. Tese de Doutorado, USP, 1985.

27 Idem, ver a Introdução à Tese de Doutorado. Registre-se também, em abordagem semelhante, o trabalho de Daniel Rótulo Decuadra, Geopolítica, Política Externa e pensamento militar brasileiros em relação ao Atlântico Sul (1964-1990). Dissertação de Mestrado, IRI/PUC-RJ, 1991.

28 O livro Geopolítica do Brasil, de Golbery do Couto e Silva, lançado em 1967, ainda é considerado por muitos a grande síntese do pensamento dos militares; ver Golbery do Couto e Silva, Conjuntura política nacional: o poder Executivo \& Geopolítica do Brasil. Rio de Janeiro: José Olympio, 1981; do General Carlos de Meira Mattos, ver A geopolítica e as projeções de poder (1977) e Brasil: geopolítica e destino (1979), ambos publicados pela José Olympio Editora, RJ. 
29 Ubiratan Borges de Macedo, “A Escola Superior de Guerra, sua ideologia e trânsito para a democracia”. Política e Estratégia, op. cit, p. 217.

30 Antonio de Arruda, A Escola Superior de Guerra: história de sua doutrina. São Paulo: GRD Brasília/INL, 1983, passim.

31 Antonio Carlos Pereira, “Aspectos totalizantes da Doutrina de Segurança Nacional”. Política e Estratégia, op. cit., p. 270.

32 ESG, Manual Básico (1977-1978). Rio de Janeiro: EMFA, Departamento de Estudos daESG, 1977.

33 ESG, Doutrina. Rio de Janeiro: ESG, 1989, p. 196-197.

34 Idem, p. 55.

35 Idem, p. 196.

$36 \quad$ Idem, p. 197.

37 Idem, p. 201.

38 Idem, ibidem.

39 Idem, p. 203.

40 Idem, ibidem. Em 1987, o Vice-Almirante João Carlos Gonçalves Caminha, forte partidário das concepções realistas, comentava sobre o assunto: "Se só cabe à Diplomacia de um dado Estado usar o Direito antes em benefício do interesse da nação do que em benefício da Justiça, então o uso do Direito pela Diplomacia deve ser conduzido dentro de um perspectiva estratégica. A Diplomacia que traz em si a repugnância pela Estratégia, ou seja, pela presença do poder no trato entre os Estados, só merece apreço nos países com vocação suicida ou naqueles sem maiores pretensões na História”. Cf. João Carlos G. Caminha, “Estratégia e relações de poder”. Política e Estratégia, vol. V, n. 4, out./dez. 1987, pp. 439-485, p. 445.

41 A doutrina militar brasileira (DMB), por sua vez, editada pela ESG, em 1983, como resultado de amplos estudos realizados desde 1969 no Curso de Comando e EstadoMaior das Forças Armadas (CEMCFA), tratava não somente das diretrizes práticas para o funcionamento efetivo do sistema militar brasileiro, em termos de preparo, adestramento e planejamento estratégico, mas também dos fundamentos sobre os quais se apoiava. Dentre esses fundamentos incluíam-se: a vocação pacífica do povo brasileiro; a tradição diplomática e os princípios da Política Externa brasileira; a busca de soluções das controvérsias sem o uso da força; e o respeito aos compromissos internacionais. A DMB elencava, ainda, os condicionantes básicos que influenciavam a doutrina militar e definiam o perfil internacional do Brasil: a) país ocidental, na defesa de valores como universalismo, soberania igualitária, autodeterminação, boa convivência e progresso dos povos; b) país latino-americano, compartilhando dos ideais e dos princípios da comunidade regional latino-americana; c) país em desenvolvimento e pertencente ao Terceiro Mundo, empenhado por uma reordenação mais justa e realista do sistema econômico mundial; d) nação democrática, “de fortes sentimentos de religiosidade, visceralmente oposta à difusão e à expansão de qualquer ideologia totalitária”. Ver Antonio Candido Graça Alvarenga, “Doutrina militar brasileira”. Revista da Escola Superior de Guerra. ano I, vol. II, n. 2, abr. 1984, pp. 61-77, p. 68. 
42 Quanto a artigos, foram consultados os seguintes periódicos: A Defesa Nacional, Revista do Clube Militar e Revista Militar Brasileira (Exército); Revista Marítima Brasileira (Marinha); Revista Aeronáutica (Aeronáutica); Revista da Escola Superior de Guerra (EMFA); Segurança e Desenvolvimento (ADESG); Política e Estratégia (Ed. Convívio); e Cadernos de Estudos Estratégicos (CEBRES).

43 Ray S. Cline, World power assessment: a calculus of strategic drift. Washington D.C., Center for Strategic and International Studies, Georgetown University, 1975.

44 Cf. Maria Regina Soares de Lima \& Zairo B. Cheibub, Relações internacionais e Política Externa brasileira: debate intelectual e produção acadêmica. Rio de Janeiro: MRE/IUPERJ, mimeo 1983, p. 20.

45 Observou-se, em nossa pesquisa dos periódicos, que a maior parte dos artigos sobre Política Externa brasileira e diplomacia, que apareciam em revistas militares, eram de autoria de diplomatas.

46 Geraldo Lesbat Cavagnari Filho, “Autonomia militar e construção da potência”, in As Forças Armadas no Brasil. Rio de Janeiro: Espaço e Tempo, 1987, p. 58 e seguintes.

47 Ver Robert Wesson (ed.), The Latin American military institution (New York: Praeger Publishers, 1986) e George Philip, The military in South American politics. London: Croom Helm, 1985.

48 Cf. Clóvis Brigagão \& Domício Proença Jr., “A projeção externa do Brasil: a questão da segurança”. Contexto Internacional, n. 7, jan./jun. 1988, pp. 85-109, p. 87.

49 Max G. Manwaring, "Elites político-militares brasileiras: semelhança e continuidade, 1964-1975”.A Defesa Nacional, n. 689, mai./jun. 1980, pp. 101-111, p. 108.

50 Ver Moniz Bandeira, Brasil-Estados Unidos: a rivalidade emergente (1950-1988). Rio de Janeiro: Civilização Brasileira, 1989, p. 235-6.

51 Nilson Vieira Ferreira Mello(Coronel), “O conflito das Malvinas e seus ensinamentos”. ADefesa Nacional, n. 706, mar./abr. 1983, pp. 31-34.

52 O regime instaurado em 1964 não rompeu relações diplomáticas com a União Soviética nem com os países da Europa Oriental (o fez apenas com Cuba). Ainda citando Castelo Branco: “No Leste Europeu encontramos Estados cuja filosofia política diverge essencialmente da nossa. Essas divergências não têm por que criar entre nós e esses países um estado de hostilidade. As relações que com eles temos podem ser mantidas e, em certos terrenos, ampliadas”. Discurso do Presidente Castelo Branco na cerimônia do Dia do Diplomata, em 31 de julho de 1964, op. cit., p. 21.

53 Em palestra na Escola de Guerra Naval, em 1985, o General Octávio Costa afirmava com franqueza: "É preciso reagir à tendência, que chegou a se configurar, para uma doutrinação ideológica voltada para inibir qualquer iniciativa autônoma e para gerar lealdades incondicionais, que poderiam nos levar ao risco de assumirmos um perfil militar caracterizado por uma formação humanística 
insuficiente, unilateral e dogmática e por uma tendência à elaboração de raciocínios simplificados, até mesmo por mentalidade preconceitusa, intolerante e maniqueísta, incapacidade, afinal, de conviver com realidades complexas." Octavio Costa, “Os militares na sociedade moderna”. Política e Estratégia, vol. IV, n. 2, abr./jun. 1986, pp. 163-173, p. 171.

54 Sobre a mudança no perfil de segurança do Brasil ver Antonio Carlos Pereira, “O pensamento estratégico brasileiro”. Política e Estratégia, vol. VI, n. 4, out./dez. 1988, pp. 750-761.

55 Cf. Armando Amorim Ferreira Vidigal, “Uma nova concepção estratégica para o Brasil - um debate necessário”. Revista Marítima Brasileira, vol. 109, n. 7/9, jul./ set. 1989, p. 49-71, p. 59-60. Dizia então o Vice-Almirante Armando Vidigal que "sem as motivações clássicas, as Forças Armadas correm o risco de 'desemprego estrutural’, isto é, de se tornarem imensas organizações sem objetivos concretos, com os militares à espera de algo que sabem não acontecerá”, p. 60.

56 Mário César Flores, “O preparo da Marinha dos próximos 10 a 30 anos. Dúvidas, comentários e sugestões”. Política e Estratégia, vol. VI, n. 4, out./dez. 1988, pp.608-616, p. 615.

57 Armando A. F. Vidigal, “Uma nova concepção estratégica para o Brasil”, op. cit., p. 71.

58 Cf. Michael J. Francis and Timothy J. Power, "South America”, in David W. Dent (ed.), Handbook of political science research on Latin America: trends from the 1960s to the 1990s. Westport: Greenwood Press, 1990, p. 356.

\section{Resumo}

O artigo trata de questões relacionadas à evolução do pensamento dos militares brasileiros, no período 1961-1989, em matéria de relações internacionais e Política Externa. Levanta algumas das limitações da interpretação crítica tradicional e analisa a concepção de política internacional prevalecente na doutrina das Forças Armadas. Procura destacar, por fim, traços distintivos que marcaram o pensamento dos militares sobre o assunto, incluindo sua vinculação com as grandes tendências históricas da diplomacia brasileira.

\section{Abstract}

The article deals with matters related to the evolution of the Brazilian military thought between 1961 and 1989, in the field of international relations and foreign policy. It raises some shortcomings of the traditional critic interpretation 
and analyses the conception of international politics prevailing in the armed forces doctrine. It tries to point out, finally, distinguishing features which have marked the military thought on the subject, including their connection with the major historical trends in Brazilian diplomacy.

Palavras-chave: Militares. Pensamento brasileiro. Política internacional. Key-words: The Military. Brazilian thought. International politics. 